\title{
A New Approach to Chemical Recycling of Polyamide 6.6 and Synthesis of Polyurethanes with Recovered Intermediates
}

\author{
Janusz Datta ${ }^{1}$ (D) Kamila Błażek ${ }^{2} \cdot$ Marcin Włoch $^{2} \cdot$ Radosław Bukowski $^{2}$
}

Published online: 27 September 2018

(c) The Author(s) 2018

\begin{abstract}
A new efficient method for the chemical decomposition of polyamide 6.6 by the glycolysis and amino-glycolysis processes was proposed. The glycolysis was conducted using the mass excess of ethylene glycol (EG) as a decomposing agent in the presence of a catalyst. Also, a mixture of EG and triethylenetetramine was used as another decomposing agent in the aminoglycolysis process. The described process of decomposition did not require the use of elevated pressure. The hydroxyl and amine numbers, rheology behavior and the presence of characteristic chemical groups in the obtained glycolysates and aminoglycolysates were determined in order to characterize the reaction products. The decomposition products were defined as non-Newtonian fluids that could be described by suitable mathematical models. The conducted studies showed that the properties of the obtained intermediates depend on the mass excess of the decomposing agent used. The resulting semiproducts are suitable for reusing in the synthesis of polyurethanes, which has been confirmed by the exemplary synthesis. In the reaction, 10 and $15 \mathrm{wt} \%$ of commercial polyol were replaced with the recovered intermediates.
\end{abstract}

Keywords Polyamide recycling $\cdot$ Chemical decomposition $\cdot$ Poly(ester urethane)s $\cdot$ Rheology $\cdot$ Mechanical properties

\section{Introduction}

It is commonly known that the amount of plastic waste has increased considerably over the last few years. In 2015, the global polymer production was estimated at 322 million tons per year [1]. This is due to the fact that plastics find use in a wide range of industrial applications, e.g. packaging, electrical and electronic industries, medicine, building and construction, motorization, and much more. In the 1990s, approximately $73 \%$ of plastic waste was stored, which is disadvantageous from the environmental point of view because many polymers are not biodegradable [2, 3]. In accordance with the Council Directive 1999/31/EC, the quantitative limits of waste disposal in landfills have been enforced and, consequently, the amount of waste decreased and the negative

Janusz Datta

janusz.datta@pg.edu.pl

1 Department of Elastomers and Rubber Technology, Institute for Engineering of Polymer Materials and Dyes, 30 Harcerska Street, 05-820 Piastow, Poland

2 Department of Polymers Technology, Faculty of Chemistry, Gdansk University of Technology, 11/12 Gabriela Narutowicza Street, 80-233 Gdansk, Poland effects on the environment were reduced [4]. Nowadays, there has been an increased interest in the further reduction of the amount of waste. There are three major types of recycling process which can be used to dispose of waste, i.e. mechanical recycling methods, chemical recycling methods and the recovery of energy. In 2014, approximately $30.8 \%$ of plastics across the European Union (EU) were stored in landfills, $29.7 \%$ were reclaimed by recycling processes, and $39.5 \%$ by the recovery of energy [1].

Polyamides (PAs) are a group of crystalline polymers which are commonly represented by two commercial products, i.e. polyamide 6 (nylon 6) and polyamide 6.6 (nylon 6.6) [5]. The most common types of polyamide are obtained in the form of fibres or thermoplastics [6]. Blends of two different types of polyamides (PA6/6.6 or PA6/12) or polyamides with other polymers, such as polypropylene or polyethylene, are another attractive alternative [7]. The hydrolytic route (ring-opening polymerization) is used to form polyamide 6 , while polyamide 6.6 is obtained via stepgrowth reactions between diamines and diacids [8]. Polyamides are characterized by high chemical resistance, and good mechanical and thermal properties [5, 9]. In order to improve the properties of aliphatic polyamides, the incorporation of aromatic moiety into an aliphatic backbone is 
applied [8]. This procedure makes it possible for polyamides to be used widely in various applications by the automotive, electrical, electronic, construction, packaging, and other industries [1]. It should be pointed out that polyamides are also used in Selective Laser Sintering (SLS) technology to build complex 3D structures. At present, polyamide 12 (PA 12 ) is the most widely commercialized material in polymeric Additive Manufacturing (AM) technologies. On the other hand, polyamide 6 could be easily utilized in SLS technology due to its advantageous thermo-mechanical properties and laser sintering processibility that is comparable to that of PA 12 [10]. Therefore, world demand for polyamides is increasing year by year. Considering the increased interest in using those materials, the related waste management problems will follow.

The mechanical recycling process is the easiest way to recycle polyamides. One of the techniques with the potential application is melt extrusion [11]. The mechanical recycling is appropriate from both an economic and environmental point of view. In practice, the use of costly waste separation and cleaning is the significant impediment to this process. Moreover, it is very difficult to identify and discern with precision PA 6 from PA 6.6. It is essential that recyclates have well-defined and repetitive properties, even after multiple processes [12]. Lozano-González et al. [13] investigated the effect of multiple processes of nylon 6 by the injection moulding method at a temperature of $235^{\circ} \mathrm{C}$. The authors observed that the physicomechanical properties of the material remained constant until the eighth cycle. Afterwards, during the multiple processes, the percentage of elongation decreased by about $70 \%$, while the molecular weight increased, most likely as a result of the recombination of broken chains.

The chemical recycling process is another possibility to reduce the amount of waste. The purpose of chemical recycling is to recover and reuse monomers [14]. This method is used for polyamides as well as polyurethanes [14-16] and polyesters $[17,18]$. The reactivity of polyamides depends on the polar amide groups present in the main polyamide chain, which can react with decomposing agents. The typical decomposing agents are ammonia (ammonolysis) [19, 20], water or steam (hydrolysis) [3, 21-23] and glycols (glycolysis) [5]. The products of the decomposition of polyamide are oligomers or small-molecular-weight chemical compounds with different physicochemical properties and functionality. The aim of polyamide depolymerization is to obtain caprolactam and hexamethylenediamine, which can be utilized in the synthesis of new polyamide or other polymers, because their properties resemble those of commercial reagents [3].

Hydrolysis and ammonolysis of polyamide have been widely described in the available literature. Wang and Zhang [23] examined hydrolysis of polyamide 6 in subcritical water. The authors replaced traditionally utilized homogeneous acids with $\mathrm{H}-$ form zeolites. Based on the conducted experiments, it was concluded that the temperature and reaction time are the decisive factors of depolymerization via hydrolysis. Moreover, the amount of water used does not affect the disintegration of nylon. On the basis of their studies, the scientists demonstrated the mechanism of degradation. Firstly, the hydrogen bonds are broken, which is followed by the formation of oligomers as a result of a nucleophilic substitution reaction between water and the carboxyl groups. Patil and Madhamshettiwar [22] optimized the conditions of hydrolytic depolymerization in the acidic medium of nylon 6.6. The scientists observed that the most effective reaction is achieved at a temperature of $80^{\circ} \mathrm{C}$, with an excess of acid. A novel, promising method described in the literature is the hydrothermal treatment of waste plastics. The aliphatic polyamides are dissolved in super-heated and supercritical water, which results in the hydrolyzed products [24, 25]. With regard to the ammonolysis of polyamide, Kalfas [20] demonstrated the mechanism of nylon disintegration, which is based on the breakage of amide bond and the dehydration of amide end-groups.

The reports on the glycolysis of nylon 6.6 are rather limited. Up to now, the glycolysis of nylon 6 was studied more accurately [26, 27]. Kim et al. [5] examined the degradation mechanism of polyamide 6.6 by ethylene glycol that is based on the decomposition of the model compound, namely, $\mathrm{N}, \mathrm{N}$ hexamethylenebis(hexamide). The authors also characterized the obtained glycolysates using GPC, GC-MS, and FTIR analysis. The process was carried out at a temperature of $275^{\circ} \mathrm{C}$ and the [PA 6.6]/[EG] molar ratio of $1: 2$. The proposed mechanism for the decomposition of polyamide 6.6 includes the formation of hexamethylenediamine, esters and another primary amine.

Our study has been undertaken in order to establish the conditions of glycolysis and amino-glycolysis of polyamide 6.6 (nylon 6.6) using ethylene glycol (EG) and triethylenetetramine (TETA) as decomposing agents. The proposed method does not require the use of elevated pressure. In the present work, the parameters such as, density, hydroxyl and amine numbers, number- average molecular weight and rheometric properties of the obtained semi-products were examined. The chemical structure of products was characterized by means of Fourier transform infrared (FTIR) spectroscopy. The aforementioned investigations were absolutely critical with reference to substituting glycolysates or aminoglycolysates for completely or partially commercial polyols in the polyurethane synthesis. Hence, this work laid out a new method of polyurethane synthesis with glycolysates (EG:PA6.6 $=2: 1,3: 1,4: 1$ ) as a part of the polyol system. The synthesis of poly(ester urethane)s was realized by a one-step method. The resulting materials were examined in relation to their mechanical properties (static tensile properties, hardness and rebound resilience), while the presence of 
characteristic chemical groups was confirmed by the FTIR analysis.

\section{Experimental}

\section{Materials}

Zytel 101L NC010, known as polyamide 6.6 (PA 6.6), was purchased from DuPont. Diammonium hydrogen phosphate $\left(M_{n}=132,07 \mathrm{~g} / \mathrm{mol}\right)$ and ethylene glycol (EG) $\left(M_{n}\right.$ $=62,07 \mathrm{~g} / \mathrm{mol})$, both purchased from POCH S.A. and used as received, were applied as a catalyst and decomposing agent, respectively. Triethylenetetramine (TETA) $\left(\mathrm{M}_{\mathrm{n}}\right.$ $=146,23 \mathrm{~g} / \mathrm{mol}$ ) was obtained from ILT Poland PVT and used as received. The synthesis of poly(ester urethane) s was realized using 4,4'-diphenylmethane diisocyanate (MDI, ONGRONAT ${ }^{\circ} 3000, \mathrm{M}_{\mathrm{w}}=250,25 \mathrm{~g} / \mathrm{mol}$, viscosity $10 \mathrm{mPa} s$ at $43{ }^{\circ} \mathrm{C}$, NCO content min. $33.4 \mathrm{wt} \%$, density $1.18 \mathrm{~g} / \mathrm{cm}^{3}$ at $43{ }^{\circ} \mathrm{C}$; BorsodChem, Hungary,) and $\alpha$, $\omega$ - dihydroxy(ethylene-butylene adipate) (POLIOS 55/20, $\mathrm{M}_{\mathrm{w}}=2000 \mathrm{~g} / \mathrm{mol}$; Purinova, Poland). 1,4-butanediol (BDO, $\mathrm{M}_{\mathrm{w}}=90.12 \mathrm{~g} / \mathrm{mol}$, purity $99 \%$, viscosity $69 \mathrm{mPa}$ at $20^{\circ} \mathrm{C}$, density $1.02 \mathrm{~g} / \mathrm{cm}^{3}$ at $25^{\circ} \mathrm{C}$; Brenntag, Poland) and 1,4diazabicyclo[2.2.2] octane (DABCO; Sigma-Aldrich) were used as a catalyst and chain extender, respectively.

\section{Glycolysis}

Glycolysis of PA 6.6 with the excess of EG as a decomposing agent with a different mass ratio $(\mathrm{PA} / \mathrm{EG}=1: 2,1: 3,1: 4$, $1: 5$ and 1:6) was carried out in a $2 \mathrm{~L}$ glass reactor equipped with Liebig condenser, temperature controller, and anchor stirrer. Firstly, EG was batched and then heated to $150{ }^{\circ} \mathrm{C}$. Next, the catalyst diammonium hydrogen phosphate ( $2 \mathrm{wt} \%)$ was added gradually and the mixture was heated to $190{ }^{\circ} \mathrm{C}$. Fifteen minutes after the temperature of reaction mixture had been stabilized, the granulated polymer was added every $5 \mathrm{~min}$ in approximately $25 \mathrm{~g}$ portions. Time of the reaction was counted starting with the addition of the last portion of the granulated plastic. Each process took ca. $1.5 \mathrm{~h}$. Afterward, the reaction mixture was cooled down to $100{ }^{\circ} \mathrm{C}$. The samples were collected and characterized by using selected methods.

\section{Amino-Glycolysis}

The amino-glycolysis of PA 6.6 with EG and TETA as decomposing agents with different mass ratios (PA/EG/ TETA $=1: 1: 1$ and 1:2:2) was carried out in a $2 \mathrm{~L}$ glass reactor equipped with Liebig condenser, temperature controller, and anchor stirrer. Firstly, the mixture of EG and TETA was batched and then heated to $150{ }^{\circ} \mathrm{C}$. Next, the catalyst diammonium hydrogen phosphate $(2 \mathrm{wt} \%)$ was added gradually, and all reagents were mixed and heated to $190{ }^{\circ} \mathrm{C}$. Fifteen minutes after the temperature of the reaction mixture had been stabilized, the granulated substance was added in portions of $25 \mathrm{~g}$ each, every $5 \mathrm{~min}$. The reaction time was counted from the point when the last portion of granulated substance was added. Each process took ca. $1.5 \mathrm{~h}$. Afterward, the reaction mixture was cooled down to $100{ }^{\circ} \mathrm{C}$. The samples of aminoglycolysates were collected and characterized by using selected methods.

\section{Synthesis of Poly(ester urethane)s}

The synthesis of poly(ester urethane)s was carried out by means of a one-step method. The synthesis was performed in bulk through a reaction between 4,4'-diphenylmethane diisocyanate (MDI), 1,4-butanediol (BDO) as a chain extender, and the mixture of polyol (POLIOS 55/20) with glycolysates (EG:PA $=2: 1,3: 1,4: 1)$ prepared in the previous step. The obtained glycolysates were mixed in an amount of $10 \mathrm{wt} \%$ with a commercial polyol. In order to partially bond free amine groups, $1 \mathrm{wt} \%$ of orthophosphoric acid was added per glycolysates used. The reaction was conducted at a temperature of $60{ }^{\circ} \mathrm{C}$ in the presence of $0.3 \mathrm{wt} \%$ of DABCO as a catalyst. The reaction mixtures were poured into a metal mould at $70{ }^{\circ} \mathrm{C}$ (dimension of mould cavity: $120 \mathrm{~mm} \times 110 \mathrm{~mm}$ $\times 2 \mathrm{~mm}$ ), cured and finally seasoned at $100{ }^{\circ} \mathrm{C}$ for $24 \mathrm{~h}$ in a laboratory oven. The codes of the obtained materials and the weight content of hard (HS) and soft (SS) segments are presented in Table 1.
Table 1 Formulations of prepared poly(ester urethane) $\mathrm{s}$ as well as hard and soft segments content in the prepared polyurethanes

\begin{tabular}{lllllll}
\hline Code of sample (\%) & $\begin{array}{l}\text { POLIOS } \\
55 / 20(\mathrm{~g})\end{array}$ & $\begin{array}{l}\text { Glycolysed } \\
\text { sample }(\mathrm{g})\end{array}$ & MDI (g) & BDO (g) & $\begin{array}{l}\text { Hard segments } \\
\text { content (wt\%) }\end{array}$ & $\begin{array}{l}\text { Soft segments } \\
\text { content (wt\%) }\end{array}$ \\
\hline PUR-2:1-10 & 54 & 6 & 40.4833 & 8.6243 & 50.5 & 49.5 \\
PUR-3:1-10 & 54 & 6 & 42.3678 & 8.7861 & 51.4 & 48.6 \\
PUR-4:1-10 & 54 & 6 & 46.4339 & 9.1351 & 53.3 & 46.7 \\
PUR-2:1-15 & 51 & 9 & 45.9850 & 9.0965 & 55.6 & 44.4 \\
PUR-3:1-15 & 51 & 9 & 48.8119 & 9.3392 & 56.8 & 43.2 \\
PUR-4:1-15 & 51 & 9 & 54.9109 & 9.8626 & 59.1 & 40.9 \\
\hline
\end{tabular}




\section{Methods of Characterization}

The presence of characteristic groups in the chemical structure of glycolysates and aminoglycolysates was determined by means of a Nicolet 8700 FTIR Spectrophotometer (Thermo Electron Corporation) and the ATR (Heated Golden Gate from Specac Ltd.) technique. Scans were recorded at room temperature in the range between 500 and $4500 \mathrm{~cm}^{-1}$. The spectra were acquired using 64 scans, with a nominal resolution of $4 \mathrm{~cm}^{-1}$.

The sample density was determined according to ISO 1675 by using a pycnometer equipped with a mercury-inglass thermometer. The measurements were realized at $25{ }^{\circ} \mathrm{C}$ and consisted of three mass determinations, i.e. the mass of dry pycnometer $\left(\mathrm{m}_{1}\right)$, the mass of pycnometer filled with distilled water $\left(\mathrm{m}_{2}\right)$ and the mass of pycnometer filled with the sample $\left(\mathrm{m}_{3}\right)$. Density was obtained using the following formula:

$\rho=\frac{m_{3}-m_{1}}{m_{2}-m_{1}} \rho_{\mathrm{H}_{2} \mathrm{O}}$,

where $\mathrm{m}_{1}$ is the mass of dry pycnometer $(\mathrm{g}) ; \mathrm{m}_{2}$ stands for the mass of pycnometer filled with distilled water $(\mathrm{g})$; and $\mathrm{m}_{3}$ is the mass of pycnometer filled with the sample $(\mathrm{g}) ; \rho_{\mathrm{H} 20}$ density of water in $\left(\mathrm{g} / \mathrm{cm}^{3}\right)$.

The hydroxyl number of each sample was determined by using a standard titration method, in accordance with ISO 2554. Each analysis was repeated at least three times, and the reported results are averages of all conducted measurements per sample. The following formula was used to calculate the hydroxyl number:

$L_{\mathrm{OH}}=\frac{\alpha\left(V_{2}-V_{1}\right) C_{\mathrm{KOH}}}{m}$,

where $\alpha$-the molar mass of potassium hydroxide $(56.1 \mathrm{~g} /$ $\mathrm{mol}) ; \mathrm{V}_{2}$ - the volume of potassium hydroxide used during blank feed titration $\left(\mathrm{cm}^{3}\right) ; \mathrm{V}_{1}$ - the volume of potassium hydroxide used during sample titration $\left(\mathrm{cm}^{3}\right) ; \mathrm{C}_{\mathrm{KOH}}$-the molar concentration of potassium hydroxide; $\mathrm{m}$-mass of sample (g).

The number- average molecular weight was calculated based on the obtained values of hydroxyl number by using the following formula:

$\bar{M}_{w}=\frac{56100 f}{L_{K} L_{\mathrm{OH}}}$,

where $\mathrm{f}$ - the functionality of the compound, assumed $\mathrm{f}=2$; 56100 - the molecular weight of potassium hydroxide ( $\mathrm{mg} /$ mol); $\mathrm{L}_{\mathrm{OH}}$-hydroxyl number (mg KOH g ${ }^{-1}$ sample); $\mathrm{L}_{\mathrm{K}}-$ acid value (mg KOH g${ }^{-1}$ sample), assumed $\mathrm{L}_{\mathrm{K}}=0$.
The amine number was determined using the industry standard method BN-69/6110-29. The following formula was selected to calculate the amine number of the obtained samples:

$L_{A}=\frac{56.1\left(V_{1}-V_{2}\right) C_{\mathrm{HCl}}}{m}$,

where $\mathrm{V}_{2}$ - the volume of hydrochloric acid used during blank feed titration $\left(\mathrm{cm}^{3}\right) ; \mathrm{V}_{1}$-the volume of hydrochloric acid used during the sample titration $\left(\mathrm{cm}^{3}\right) ; \mathrm{C}_{\mathrm{HCl}}$-the molar concentration of hydrochloric acid; $\mathrm{m}-\mathrm{a}$ mass of sample (g).

Rheological measurements were carried out using a rotary rheometer R/S-CPS+ (Brookfield) equipped with a cone-plate arrangement. The measurements were realized with a controlled shear rate, but different programs were applied for glycolysates and aminoglycolysates. The following program was used for glycolysates: increasing shear rate from 0 to $300 \mathrm{~s}^{-1}$ for $150 \mathrm{~s}$; constant shear rate $\left(300 \mathrm{~s}^{-1}\right)$ for $30 \mathrm{~s}$; and decreasing shear rate from 300 to $0 \mathrm{~s}^{-1}$ for $150 \mathrm{~s}$. Every sample was analyzed at two different temperatures, i.e. -25 and $50{ }^{\circ} \mathrm{C}$. In the case of aminoglycolysates, the measurements were conducted using the following program: increasing shear rate from 0 to $150 \mathrm{~s}^{-1}$ for $75 \mathrm{~s}$; the constant shear rate of a certain value for $15 \mathrm{~s}$; decreasing shear rate from 150 to $0 \mathrm{~s}^{-1}$ for $75 \mathrm{~s}$. The resulting measurements were analyzed by means of Rheo3000 software. The viscosity and flow curves at different temperatures were plotted based on the rheological measurements.

Static tensile tests (i.e. tensile strength and elongation at break) were performed using a Universal Testing Machine (Zwick/Roell Z020) at room temperature, in accordance with ISO 37 . Test samples were cut into the standard shape of the dumbbell (width ca. $6 \mathrm{~mm}$, thickness ca. $2 \mathrm{~mm}$, length $115 \mathrm{~mm}$ ), while the gauge length was equal $25 \mathrm{~mm}$. The measurements were performed at a cross-head speed equal $100 \mathrm{~mm} / \mathrm{min}$. The reported results are averages calculated from five independent determinations per specimen.

Hardness was measured according to the ISO 868 standard using an electronic Shore type D durometer (Zwick Roell HPE 3010). The instrument was applied perpendicularly to the test sample for $3 \mathrm{~s}$. The reported results are averages of ten independent measurements.

Rebound resilience was determined using a Schob type machine (Gibitre Instruments) according to the ISO 4662 standard. The specimens were $29 \mathrm{~mm}$ in diameter and $12 \mathrm{~mm}$ in height. The results are averages calculated from five independent measurements per specimen. 


\section{Results and Discussion}

\section{Characterization of Glycolysates and Aminoglycolysates}

The glycolysis and amino-glycolysis processes were carried out for different mass ratios of polyamide 6.6 and decomposing agents (considering the molar mass of repeating units). Based on the data presented in Table 2, it is apparent that a large excess of decomposing agents per repeating units in PA 6.6 was used. The solid samples were obtained as a result of amino-glycolysis, while the samples resulting from the glycolysis reaction were in the liquid state.

The calculated values of number- average molecular weight ranged from 91.02 to $254.40 \mathrm{~g} \mathrm{~mol}^{-1}$, as presented in Table 2. These results testify to the fact that the obtained products are low-molecular-weight compounds, while the reaction yield was as expected. This finding is undoubtedly favorable because the obtained compounds can be used in the synthesis of polyurethanes.

Changes in the density, and the hydroxyl and amine numbers of the obtained glycolysates and aminoglycolysates are presented in Table 3. As can be seen, the density of glycolysates decreased with the increasing amount of EG acting as a decomposing agent. This is due to the fact that EG has a lower density than the glycolysates $\left(1.1105 \pm 0.0012 \mathrm{~g} / \mathrm{cm}^{3}\right)$. The obtained glycolysates had a density ranging from $1.1355 \pm 0.0003$ to $1.1259 \pm$ $0.0006 \mathrm{~g} / \mathrm{cm}^{3}$ for samples GL 2/1 and GL 6/1, respectively. A similar effect was observed for the produced aminoglycolysates. The density of aminoglycolysates decreased as the amount of decomposing agent increased. The density of the final products depended on the low-density amine used in the reaction $\left(0.98 \mathrm{~g} / \mathrm{cm}^{3}\right.$; ILT Poland PVT data sheet) and ranged from $1.0864 \pm 0.0004$ to $1.0712 \pm$ $0.0005 \mathrm{~g} / \mathrm{cm}^{3}$.

The obtained values of hydroxyl number ranged between $441.03 \pm 51.89$ and $1232.75 \pm 13.12 \mathrm{mg} \mathrm{KOH}$ $\mathrm{g}^{-1}$ (see Table 3). It is noteworthy that the aminoglycolysates displayed lower hydroxyl numbers than the glycolysates. It is evident that the hydroxyl number increased with the increasing amount of EG used as a decomposing agent. This can be explained by the presence of partially unreacted EG in the post-reaction products. Furthermore, EG has a high value of hydroxyl number, i.e. $1462 \pm$ $39.42 \mathrm{mg} \mathrm{KOH} \mathrm{g}{ }^{-1}$. The high value of standard deviation indicates that the products obtained in the process are heterogeneous, which may be due to the presence of monomeric as well as oligomeric compounds. A longer reaction time would increase the degradation degree of
Table 2 Codes, numberaverage molecular weight and state matter of prepared glycolysed and aminoglycolysed samples and formulation of applied decomposing agents
Table 3 Characteristics of obtained glycolysed and aminoglycolysed samples-density, hydroxyl and amine number

\begin{tabular}{|c|c|c|c|c|c|c|c|c|}
\hline \multirow[t]{2}{*}{ Code of sample } & \multicolumn{3}{|c|}{ Mass ratio } & \multicolumn{3}{|c|}{ Molar ratio } & \multirow[t]{2}{*}{$\bar{M}_{w}(\mathrm{~g} / \mathrm{mol})$} & \multirow[t]{2}{*}{ State of matter } \\
\hline & PA 6.6 & EG & TETA & PA $6.6^{\mathrm{a}}$ & EG & TETA & & \\
\hline GL 2/1 & 1 & 2 & - & 1 & 7.3 & - & 165.7 & Liquid \\
\hline GL 3/1 & 1 & 3 & - & 1 & 10.9 & - & 143.2 & Liquid \\
\hline GL 4/1 & 1 & 4 & - & 1 & 14.6 & - & 110.8 & Liquid \\
\hline GL 5/1 & 1 & 5 & - & 1 & 18.2 & - & 97.6 & Liquid \\
\hline GL $6 / 1$ & 1 & 6 & - & 1 & 21.5 & - & 91.0 & Liquid \\
\hline AmGL 1/1/1 & 1 & 1 & 1 & 1 & 3.6 & 1.5 & 254.4 & Solid \\
\hline AmGL 2/2/1 & 1 & 2 & 2 & 1 & 7.3 & 3.1 & 227.3 & Solid \\
\hline
\end{tabular}

${ }^{\mathrm{a}} \mathrm{A}$ molar mass of repeating units

\begin{tabular}{lccc}
\hline Code of sample & Density $\left(\mathrm{g} / \mathrm{cm}^{3}\right)$ & $\mathrm{I}_{\mathrm{OH}}\left(\mathrm{mg} \mathrm{KOH} \mathrm{g}^{-1}\right)$ & $\mathrm{I}_{\mathrm{NH}}\left(\mathrm{mg} \mathrm{KOH} \mathrm{g}^{-1}\right)$ \\
\hline GL 2/1 & $1.1355 \pm 0.0003$ & $676.99 \pm 26.49$ & $19.47 \pm 1.33$ \\
GL 3/1 & $1.1321 \pm 0.0005$ & $802.41 \pm 34.46$ & $18.22 \pm 0.76$ \\
GL $4 / 1$ & $1.1317 \pm 0.0004$ & $1012.76 \pm 26.72$ & $16.00 \pm 0.43$ \\
GL 5/1 & $1.1284 \pm 0.0006$ & $1149.93 \pm 44.39$ & $10.75 \pm 0.12$ \\
GL 6/1 & $1.1259 \pm 0.0006$ & $1232.75 \pm 13.12$ & $9.67 \pm 0.12$ \\
AmGL 1/1/1 & $1.0864 \pm 0.0004$ & $441.03 \pm 51.89$ & $372.57 \pm 16.64$ \\
AmGL 2/2/1 & $1.0712 \pm 0.0005$ & $493.63 \pm 29.02$ & $453.65 \pm 7.59$ \\
EG & $1.1105 \pm 0.0012$ & $1462.42 \pm 39.42$ & - \\
PA 6.6 & $1.1628 \pm 0.0063$ & - & - \\
TETA & $0.9750 \pm 0.0009$ & - & $1131.88 \pm 2.78$ \\
\hline
\end{tabular}


oligomeric compounds. In consequence, a mixture of lowmolecular-weight compounds could be obtained.

The obtained values of amine number ranged from 9.67 \pm 0.12 to $19.47 \pm 1.33 \mathrm{mg} \mathrm{KOH} \mathrm{g}^{-1}$ for the glycolysates. In the case of aminoglycolysates, the amine number was approximately $400 \mathrm{mg} \mathrm{KOH} \mathrm{g}^{-1}$. Based on the results presented in Table 3, it is apparent that the amine number decreased with the increasing amount of EG. This was probably caused by the presence of partially unreacted EG in the mixture of the reaction products. It is noticeable that the amine number of aminoglycolysates is significantly higher than that of glycolysates. This relationship is due to the fact that the reaction products are composed of nonreacted diamines.

The proposed mechanism of polyamide 6.6 glycolysis caused by the reaction with an excess of the decomposing agent is presented in Scheme 1. At the beginning of the process, the oligomeric compounds with the hydroxyl and/or amine end-groups are obtained. In the final stage, the mixture of low-molecular-weight products, specifically unreacted ethylene glycol, hexamethylenediamine or a compound with $\beta$-hydroxyethylester end-groups can be obtained $[5,28]$.
In the case of amino-glycolysis, the obtained oligomeric compounds can have amine end-groups derived from triethylenetetramine used as a decomposing agent. In both types of the aforementioned chemical decomposition, esters and primary amines can also be obtained. The proposed mechanism of the reaction is presented in Scheme 2. The presence of characteristic groups in the chemical structure of aminoglycolysates and glycolysates was confirmed by the FTIR analysis, as presented further in this paper.

The presence of characteristic groups in the chemical structure of obtained samples was determined by means of FTIR spectroscopy, as depicted in Fig. 1 (spectra of glycolysates) and Fig. 2 (spectra of aminoglycolysates). A comparison of typical vibrations and their intensity for both types of material is presented in Table 4 . The characteristic stretching vibration of hydroxyl group in the $3100-3500 \mathrm{~cm}^{-1}$ range was observed in both types of samples. Furthermore, the strong absorption bands at 1058 and $871 \mathrm{~cm}^{-1}$ corresponding to the stretching vibrations of $\mathrm{C}-\mathrm{OH}$ and $\mathrm{OC}-\mathrm{C}$ groups, respectively, were observed in the spectra of obtained glysolysates and aminoglycolysates. This finding indicates that the partially unreacted EG plays a key role among the reaction products [29]. The strong<smiles>CCCCCCCNC(=O)CCCCC(=O)NCCCCCCN</smiles>

Scheme 1 Probable products of polyamide 6.6 decomposition caused by the reaction with an excess of ethylene glycol. Adapted from Kim et al. [5] 
Scheme 2 Probable products of polyamide 6.6 decomposition caused by the reaction with an excess of ethylene glycol and triethylenetetramine

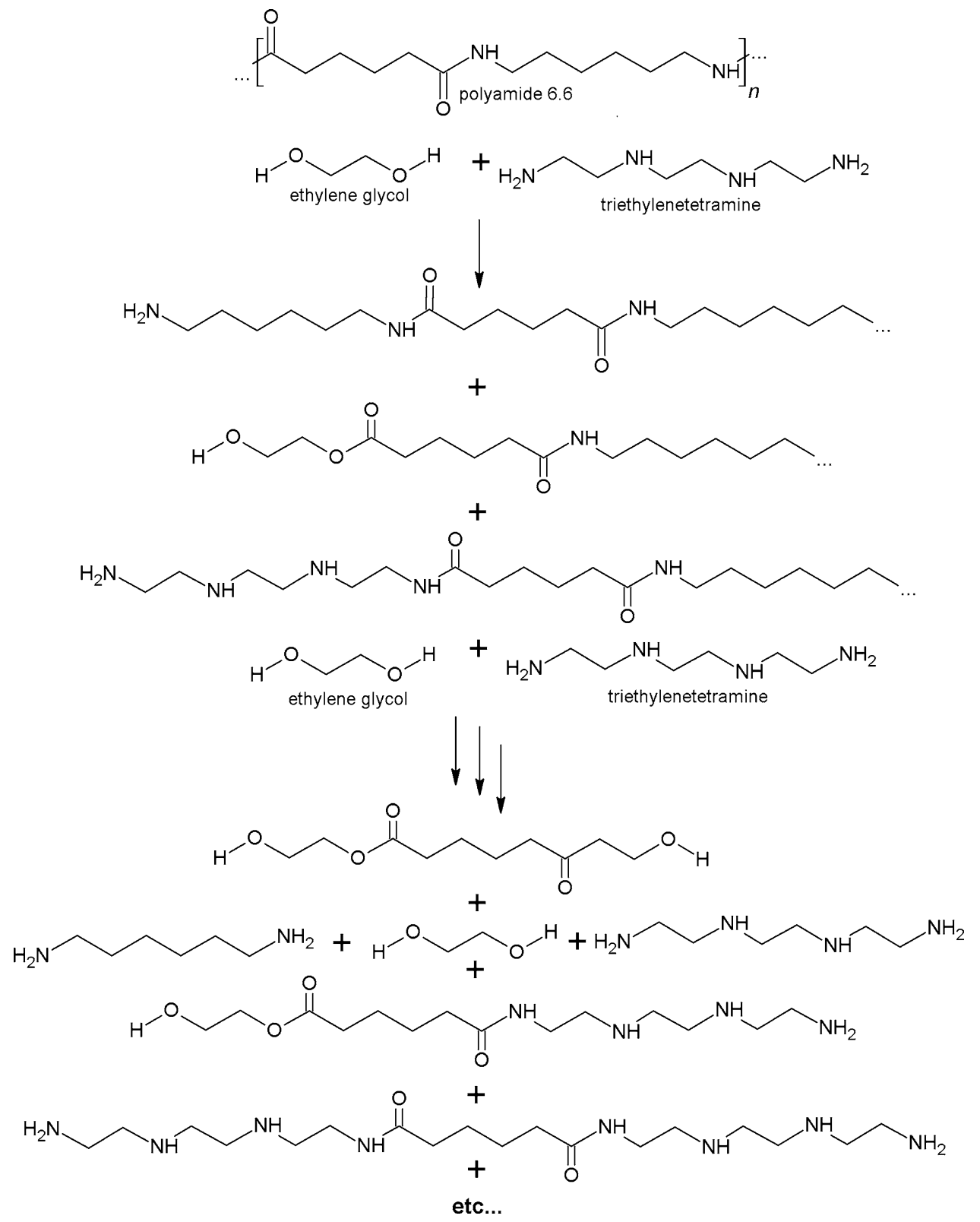




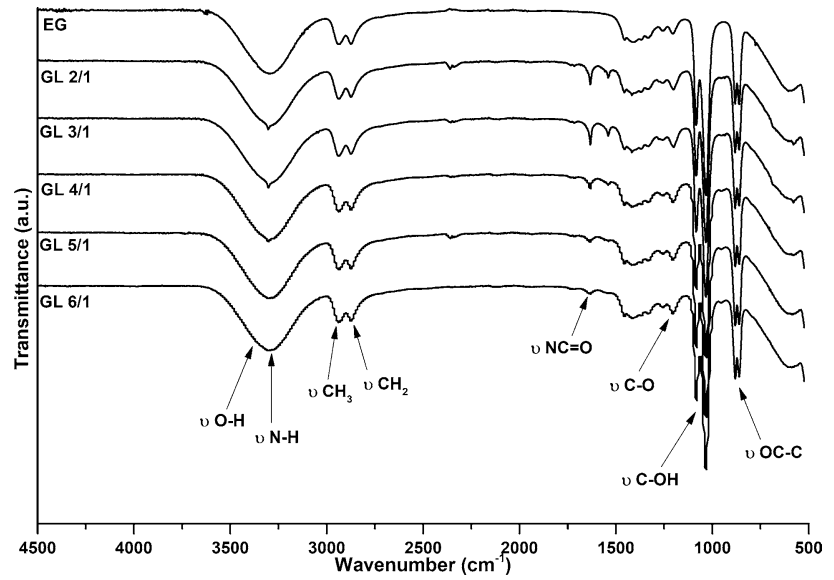

Fig. 1 The differences between the FTIR spectra of glycolysates obtained by means of glycolysis of PA 6.6 with EG as a decomposing agent for different mass ratios $(\mathrm{PA} / \mathrm{EG}=1: 2$. 1:3.1:4. 1:5 and 1:6)

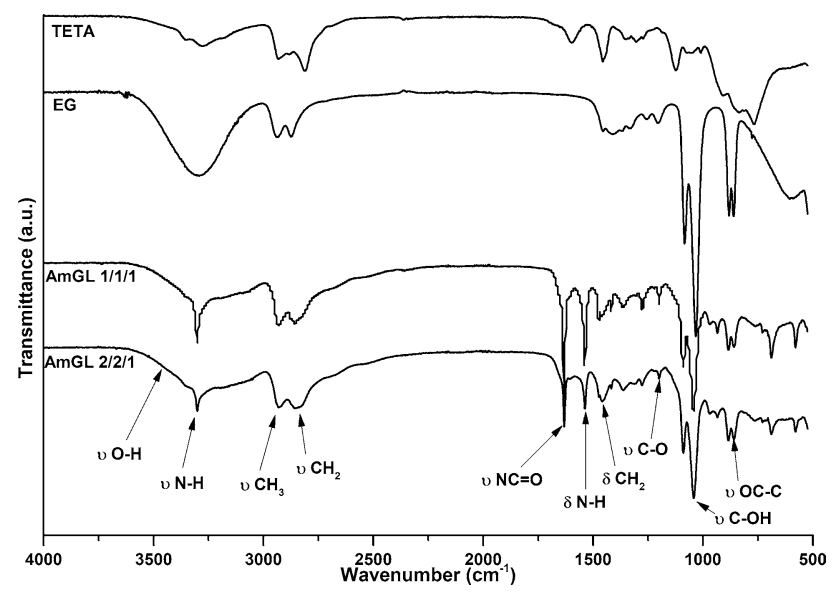

Fig. 2 The differences between the FTIR spectra of aminoglycolysates obtained by means of amino-glycolysis of PA 6.6 with EG and TETA as decomposing agents for different mass ratios (PA/EG/TETA $=1: 1: 1$ and $1: 2: 2$ )

to the amine groups. It should be assumed that the excess of EG does not affect the chemical structure of obtained products. The chemical structures of obtained glycolysates and aminoglycolysates were compared. In the case of aminoglycolysates, a new bending vibration appeared in the $1300-500 \mathrm{~cm}^{-1}$ range. The absorption bands at 1276 and $686 \mathrm{~cm}^{-1}$ correspond to the stretching vibrations of $-\mathrm{C}-\mathrm{N}$ group as well as deformation vibration of $-\mathrm{NH}$ in primary amines. This can be explained by the presence of partially unreacted TETA in the mixture of products after the decomposition process. In addition, the peak at $576 \mathrm{~cm}^{-1}$ is attributable to deformation vibration of $-\mathrm{C}=\mathrm{O}$ group in amides. The peak at $3300 \mathrm{~cm}^{-1}$ assigned to bending vibrations of $-\mathrm{NH}$, and the absorption bands at $1631 \mathrm{~cm}^{-1}$ and $1537 \mathrm{~cm}^{-1}$
Table 4 Assignments, wavenumbers and intensity of the bands in the FTIR spectra of prepared glycolysed (GL) and amino-glycolysed (AmGL) samples

\begin{tabular}{llll}
\hline Wavenumber $\left(\mathrm{cm}^{-1}\right)$ & Assignments & \multicolumn{2}{l}{ Intensity } \\
\cline { 3 - 4 } & & $\mathrm{GL}$ & $\mathrm{AmGL}$ \\
\hline 3300 & $\nu \mathrm{N}-\mathrm{H}$ & $\mathrm{w}$ & $\mathrm{s}$ \\
3282 & $\nu \mathrm{O}-\mathrm{H}$ & $\mathrm{s}$ & $\mathrm{m}$ \\
2935 & $\nu \mathrm{CH}_{3}$ & $\mathrm{~s}$ & $\mathrm{~s}$ \\
2852 & $\nu \mathrm{CH}_{2}$ & $\mathrm{~s}$ & $\mathrm{~s}$ \\
1631 & $\nu \mathrm{NC}=\mathrm{O}$ & $\mathrm{m}$ & $\mathrm{vs}$ \\
1537 & $\delta \mathrm{N}-\mathrm{H}$ & $\mathrm{w}$ & $\mathrm{s}$ \\
1455 & $\delta \mathrm{CH} 2$ & $\mathrm{vw}$ & $\mathrm{w}$ \\
1276 & $\nu \mathrm{C}-\mathrm{N}$ & - & $\mathrm{w}$ \\
1200 & $\nu \mathrm{C}-\mathrm{O}$ & $\mathrm{w}$ & $\mathrm{w}$ \\
1058 & $\nu \mathrm{C}-\mathrm{OH}$ & $\mathrm{vs}$ & $\mathrm{vs}$ \\
871 & $\nu \mathrm{OC}-\mathrm{C}$ & $\mathrm{s}$ & $\mathrm{s}$ \\
686 & $\gamma \mathrm{N}-\mathrm{H}$ & - & $\mathrm{m}$ \\
576 & $\delta \mathrm{NC}=\mathrm{O}$ & - & $\mathrm{w}$ \\
\hline
\end{tabular}

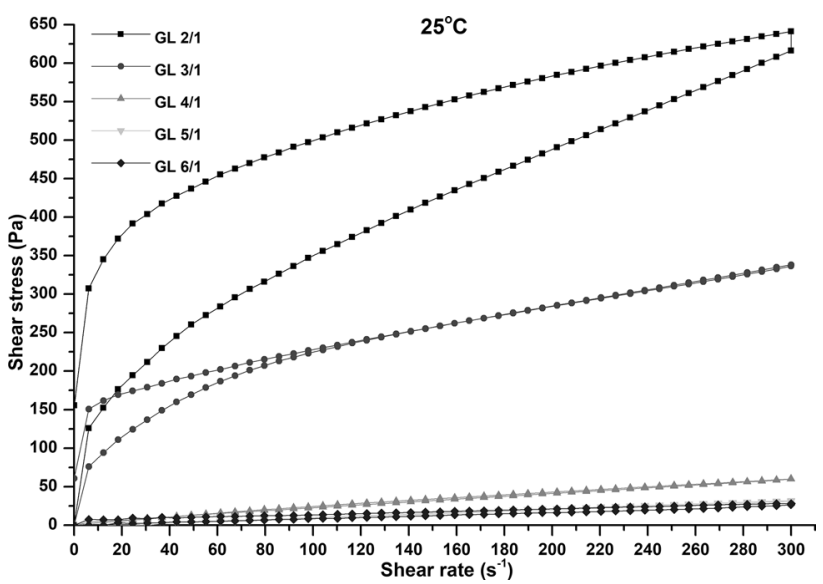

Fig. 3 Rheological flow curves of glycolysates obtained for different mass ratios $(\mathrm{PA} / \mathrm{EG}=1: 2,1: 3,1: 4,1: 5$ and 1:6) at a test temperature of $25^{\circ} \mathrm{C}$

respectively attributable to bending vibrations of $-\mathrm{NC}=\mathrm{O}$ and $-\mathrm{N}-\mathrm{H}$ groups in amides are more intensive compared to the corresponding peaks in the spectra of glycolysates. This suggests that the decomposition of PA 6.6, with TETA as a decomposing agent, is less efficient. Moreover, a decrease in the peak intensity corresponding to the vibration of amide group, and an increase in the peak intensity characteristic for amines and glycols were observed. This finding is comparable with the results obtained for the glycolysates, and is associated with the amount of decomposing agents in the mixture of products.

In Figs. 3, 4, 5, the rheograms of glycolysates at 25 and $50{ }^{\circ} \mathrm{C}$, and of aminoglycolysates at $80^{\circ} \mathrm{C}$ are presented. The 


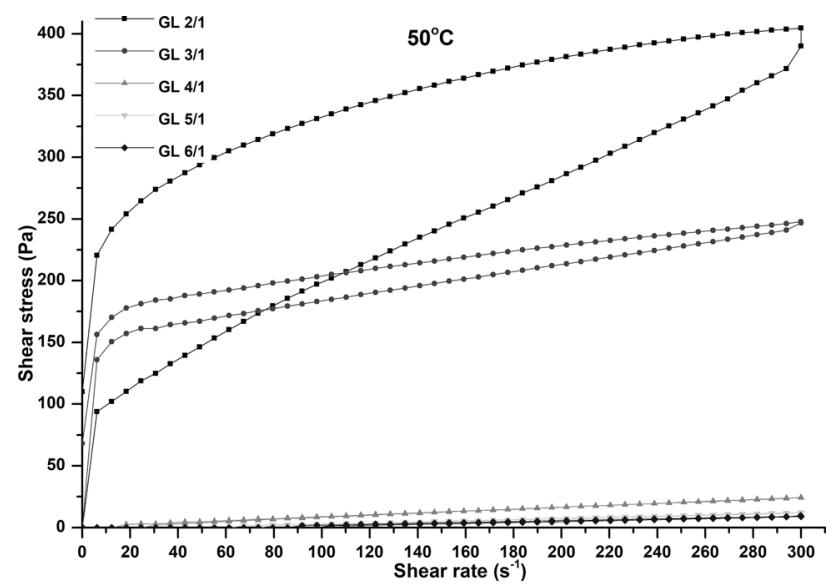

Fig. 4 Rheological flow curves of glycolysates obtained for different mass ratios $(\mathrm{PA} / \mathrm{EG}=1: 2,1: 3,1: 4,1: 5$ and 1:6) at a test temperature of $50{ }^{\circ} \mathrm{C}$

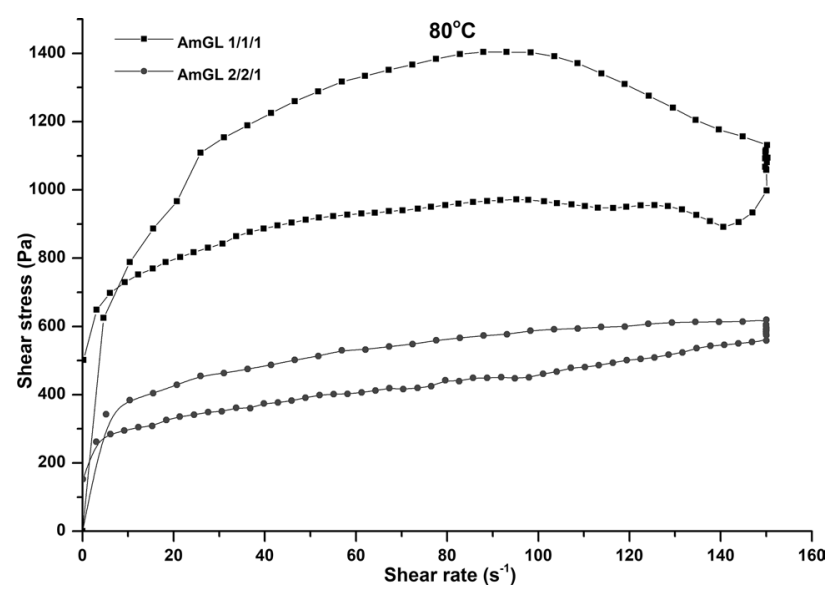

Fig. 5 Flow curves of aminoglycolysates obtained for different mass ratios $(\mathrm{PA} / \mathrm{EG} / \mathrm{TETA}=1: 1: 1(\mathbf{a}), 2: 2: 1(\mathbf{b}))$ at a test temperature of $80{ }^{\circ} \mathrm{C}$ characterization of rheological properties of a given material is significant for optimizing the polymer processing, where temperature and pressure play an important role [29]. Different temperatures were chosen based on the sample ability to shear flow. The shape of the curves demonstrates that the shear stress increased with increasing shear rate. Moreover, at higher test temperatures, the shear stress was smaller in all cases. The rising curves are located under the return, which could indicate that the obtained samples are characterized by thixotropic behavior. At $25^{\circ} \mathrm{C}$, the maximum values of shear stress reached $641,338,60,32$ and 28 for samples GL 2/1, GL 3/1, GL 4/1, GL 5/1 and GL 6/1, respectively. At a higher test temperature, a decrease in shear stress was observed for all samples. It is visible in the graphs that the hysteresis loops formed. For samples GL 2/1, GL 3/1, AmGL 1/1/1 and AmGL 2/2/1, the hysteresis loops are extensive, while for samples GL 4/1, GL 5/1 and 6/1, they are narrower. The phenomenon is characteristic for thixotropic fluids, and it is connected to the content of molecules with chains of different lengths. The chemical compounds with longer chains have a tendency to move at a higher temperature [15]. The surface area of the loop defines the energy used during the breakdown of chemical structure [31]. The most unstable characteristics and the highest fluctuation of shear stress, were observed at $80{ }^{\circ} \mathrm{C}$ in case of aminoglycolysates coded as AmGL 1/1/1. The maximum values of shear stress were about 1400 and 614 for samples AmGL 1/1/1 and AmGL 2/2/1, respectively.

In Table 5, the parameters of the applied Ostwald (also known as the Power Law) and Herschel-Bulkley rheological models are presented. These mathematical models of rheological behavior are mostly employed to characterize non-Newtonian fluids. The Herschel- Bulkley model is specifically used to describe fluids characterized by nonlinear behavior and displaying the yield stress. The Ostwald model is usually dedicated to shear-thinning fluids without
Table 5 Model functions based on rheological data for glycolysed and aminoglycolysed samples

\begin{tabular}{lllllllll}
\hline Sample & $\mathrm{T}\left({ }^{\circ} \mathrm{C}\right)$ & Model & Equation & $\tau_{\mathrm{o}}(\mathrm{Pa})$ & $\mathrm{m}\left(\mathrm{Pa} \cdot \mathrm{s}^{\mathrm{n}}\right)$ & $\mathrm{n}$ & $\Sigma$ & $\mathrm{R}^{2}$ \\
\hline GL 2/1 & 25 & Ostwald & $\tau=k \cdot \gamma^{n}$ & - & 151.05 & 0.2311 & 71.617 & 0.9787 \\
& 50 & Ostwald & $\tau=k \cdot \gamma^{n}$ & - & 111.67 & 0.1950 & 61.571 & 0.9604 \\
GL 3/1 & 25 & Ostwald & $\tau=k \cdot \gamma^{n}$ & - & 132.29 & 0.2261 & 20.324 & 0.9938 \\
& 50 & Ostwald & $\tau=k \cdot \gamma^{n}$ & - & 82.85 & 0.1129 & 10.052 & 0.9980 \\
GL 4/1 & 25 & Hershel-Bulkley & $\tau=\tau_{o}+k \cdot \gamma^{n}$ & 0.3809 & 0.4365 & 0.8604 & 0.7748 & 0.9978 \\
& 50 & Hershel-Bulkley & $\tau=\tau_{o}+k \cdot \gamma^{n}$ & 0.1931 & 0.1025 & 0.9565 & 0.2684 & 0.9983 \\
GL 5/1 & 25 & Ostwald & $\tau=k \cdot \gamma^{n}$ & - & 0.0574 & 1.1071 & 0.7105 & 0.9935 \\
& 50 & Ostwald & $\tau=k \cdot \gamma^{n}$ & - & 0.0072 & 1.3026 & 0.1799 & 0.9966 \\
GL 6/1 & 25 & Ostwald & $\tau=k \cdot \gamma^{n}$ & - & 1 & 0.5426 & 3.2461 & 0.9641 \\
& 50 & Ostwald & $\tau=k \cdot \gamma^{n}$ & - & 0.0026 & 1.4340 & 0.3650 & 0.9744 \\
AmGL 1/1/1 & 80 & Ostwald & $\tau=k \cdot \gamma^{n}$ & - & 670.74 & 0.1029 & 184.63 & 0.9701 \\
AmGL 2/2/1 & 80 & Ostwald & $\tau=k \cdot \gamma^{n}$ & - & 179.84 & 0.2038 & 184.36 & 0.8886 \\
\hline
\end{tabular}


yield stress [32]. All measurements were analyzed using Rheo3000 software. With reference to data presented in Table 5, all prepared samples were analyzed by means of the Ostwald model, with an exception of sample GL 4/1. For this specific sample, the yield stress $\left(\tau_{\mathrm{o}}\right)$ amounted to $0.38 \mathrm{~Pa}$ at $25{ }^{\circ} \mathrm{C}$, and $0.19 \mathrm{~Pa}$ at $50{ }^{\circ} \mathrm{C}$. Samples GL 6/1 (at $50{ }^{\circ} \mathrm{C}$ ) and GL 5/1 (at 25 and $50{ }^{\circ} \mathrm{C}$ ) had the flow index (n) values greater than 1 , thus they displayed dilatant behavior [32]. This type of fluid is characterized by being thicker under applied stress. The dilatant behavior of the aforementioned samples was also confirmed by the viscosity curves presented in Figs. 6 and 7. The viscosity of these samples increased proportionally with increasing shear rate. The remaining samples behaved as pseudoplastic fluids, meaning that they became thinner with increasing shear rate. The consistency index $(\mathrm{m})$ gives information about the viscosity of the material. The lower the consistency index, the lower the viscosity of the fluid [15]. According to the data presented in Table 5, the viscosity of the obtained samples decreased with the increasing amount of decomposing agent used. The viscosity drop was also observed as a result of increased test temperature.

In Figs. 6, 7, 8, the obtained viscosity curves at different temperatures for all prepared samples are depicted. The same testing parameters as for the flow curves were used. It can be observed that samples GL 2/1 and GL 3/1 exhibited shear thinning at 25 and $50{ }^{\circ} \mathrm{C}$. At both temperatures, the viscosity decreased with increasing shear rate, while at $300 \mathrm{~s}^{-1}$, the viscosity reached a constant value. The same tendency was also observed for samples AmGL 1/1/1 and AmGL 2/2/1. On the basis of viscosity curves, the aforementioned samples were described as non-Newtonian pseudoplastic fluids. The observed decrease in viscosity was connected to the physical breakage of crosslinks [33]; it improved the mobility of molecules and the free volume between them [29, 34]. In

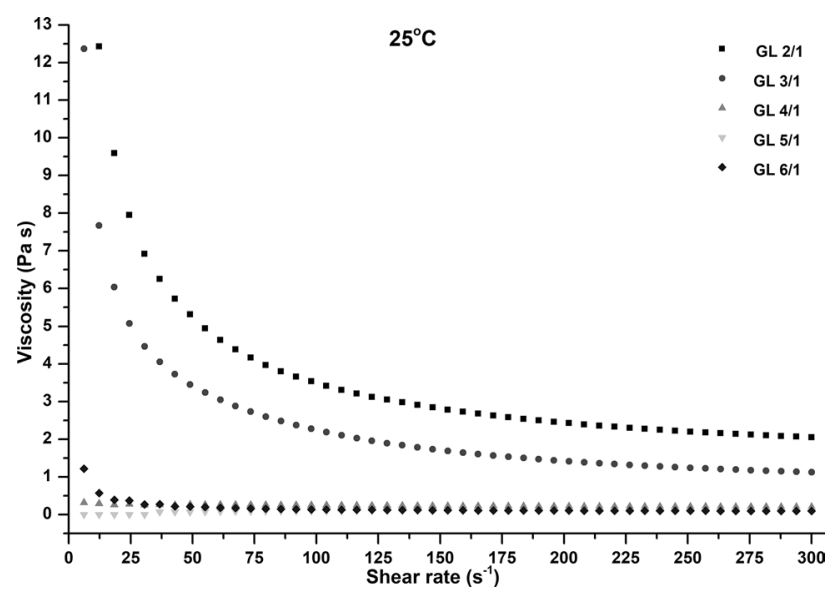

Fig. 6 Viscosity curves of glycolysates obtained for different mass ratios $\left(\mathrm{PA} / \mathrm{EG}=1: 2,1: 3,1: 4,1: 5\right.$ and 1:6) at a temperature of $25^{\circ} \mathrm{C}$

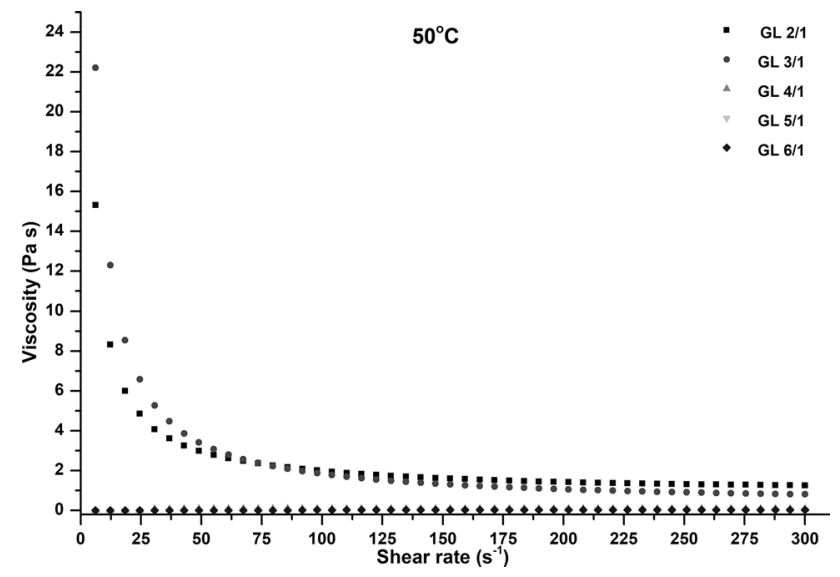

Fig. 7 Viscosity curves of glycolysates obtained for different mass ratios $\left(\mathrm{PA} / \mathrm{EG}=1: 2,1: 3,1: 4,1: 5\right.$ and 1:6) at a temperature of $50{ }^{\circ} \mathrm{C}$

the case of sample GL $6 / 1$ at $25^{\circ} \mathrm{C}$, the viscosity decreased with increasing shear rate. However, at a higher temperature $\left(50^{\circ} \mathrm{C}\right)$, the same sample displayed dilatant behavior. Samples GL 4/1 and GL 5/1 exhibited shear thickening behavior at both temperatures until reaching the plateau of limit viscosity, but this phenomenon is poorly visible on the obtained curves. The presented viscosity curves are in agreement with the results from mathematical modeling, as shown in Table 5.

In Fig. 9, the mean values of viscosity of the obtained glycolysates and aminoglycolysates for different temperatures are presented. The average viscosity was determined for the shear rate of $300 \mathrm{~s}^{-1}$. Under these conditions, the viscosity reached a constant value (plateau). It follows from the diagram that the higher content of decomposing agents in the reaction mixture resulted in a decrease in viscosity. Moreover, it can be seen that the viscosity decreased with

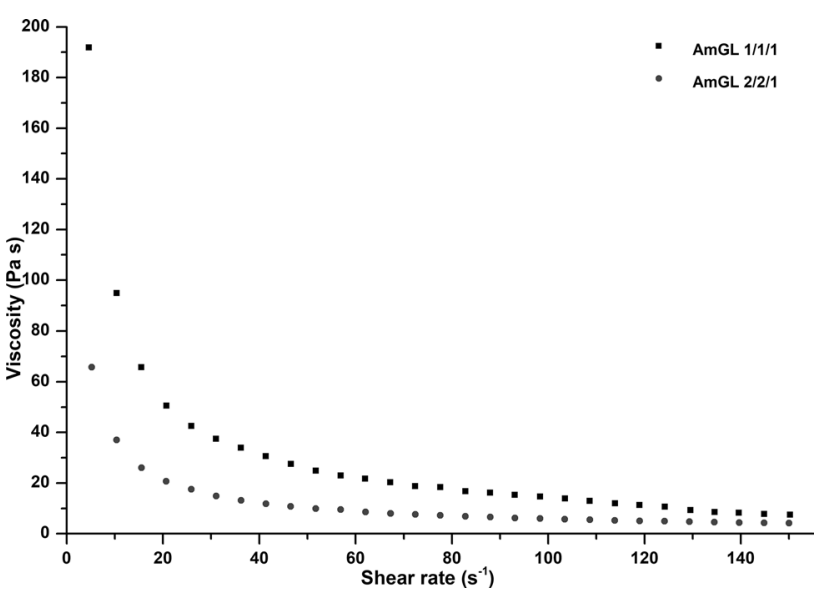

Fig. 8 Viscosity curves of aminoglycolysates obtained for different mass ratios $(\mathrm{PA} / \mathrm{EG} / \mathrm{TETA}=1: 1: 1,1: 2: 2)$ at a temperature of $80{ }^{\circ} \mathrm{C}$ 


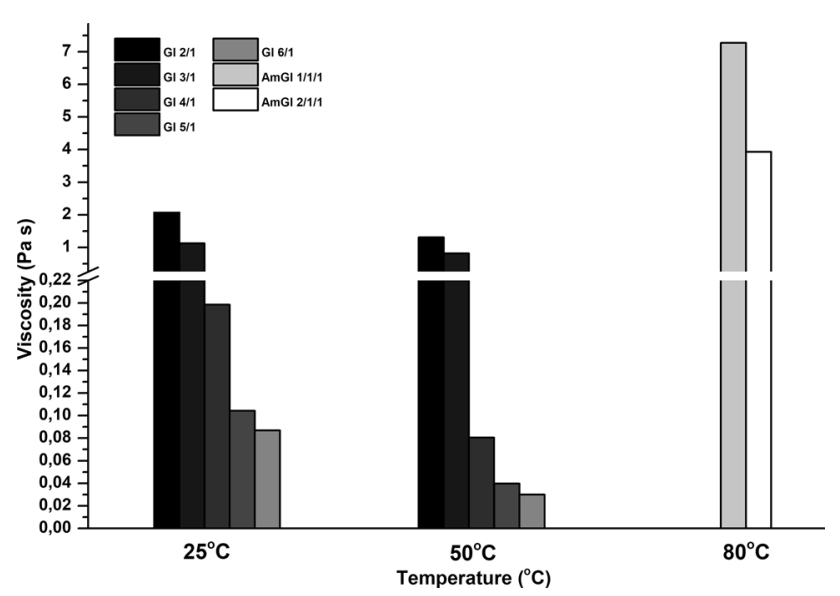

Fig. 9 The average viscosity of glycolysates obtained for different mass ratios (PA/EG = 1:2, 1:3, 1:4, 1:5 and 1:6) at temperatures of 25 and $50{ }^{\circ} \mathrm{C}$, and the average viscosity of aminoglycolysates obtained at a temperature of $80^{\circ} \mathrm{C}$

increasing temperature. In comparison to glycolysates, the viscosity of aminoglycolysates was much larger than that of other samples shown in Fig. 9. The viscosity of aminoglycolysate samples was related to the content of solvolysing agent. The viscosity increased as the number of agents decreased. The average viscosity values of samples AmGL 2:2:1 and AmGL 1:1:1 were 10.81 and 26.43 Pa s, respectively. The high viscosity of amino- glycolysates in comparison to glycolysates depended on the presence of partially unreacted diamine, which has a higher viscosity than glycol.

\section{Characterization of Poly(ester urethane)s}

The analysis of FTIR spectra (Figs. 10, 11) confirms the presence of characteristic groups in the chemical structure of synthesized poly(ester urethane)s containing 10 and 15 wt.\% of glycolysates, the latter being obtained with different weight ratios (EG:PA6.6 = 2:1, 3:1, 4:1). The FTIR spectra recorded for the samples with recovered intermediates have been compared with the spectra of poly(ester urethane) synthesized without glycolysates. The registered spectra did not differ significantly, while slight differences in the intensity of absorbance bands were observed. In the case of all prepared polyurethanes, the band attributable to free isocyanate group in the range from 2250 to $2270 \mathrm{~cm}^{-1}$ was not detected. This finding confirms that the reaction between the isocyanate and hydroxyl groups had been successfully completed under applied conditions [35]. The most important bands assigned to the characteristic vibrations of urea bond are stretching vibrations of $\mathrm{N}-\mathrm{H}$ group registered at $3300 \mathrm{~cm}^{-1}$, and a double peak in the $1680-1740 \mathrm{~cm}^{-1}$ range corresponding to stretching vibrations of carbonyl $(\mathrm{C}=\mathrm{O})$ group. The spectra demonstrate that the peak at $3300 \mathrm{~cm}^{-1}$ becomes bigger with increasing hard segment content [36]. The absorption band at $1700 \mathrm{~cm}^{-1}$ corresponds to the hydrogen-bonded carbonyl groups, while that at $1725 \mathrm{~cm}^{-1}$ is attributable to the free carbonyl groups. The noticeable changes in the band intensity at $1700 \mathrm{~cm}^{-1}$ with the increased amount of glycolysate intermediates is associated with the hydrogen bonding interactions [37]. The out-of-plane bending of $\mathrm{N}-\mathrm{H}$ groups was found at $1596 \mathrm{~cm}^{-1}$. The bond assigned to the stretching vibrations of $\mathrm{C}-\mathrm{N}$ groups in the urethane
Fig. 10 FTIR spectra of prepared poly(ester urethane) $\mathrm{s}$ in which polyol has been partially replaced by $10 \mathrm{wt} \%$ of glycolysates

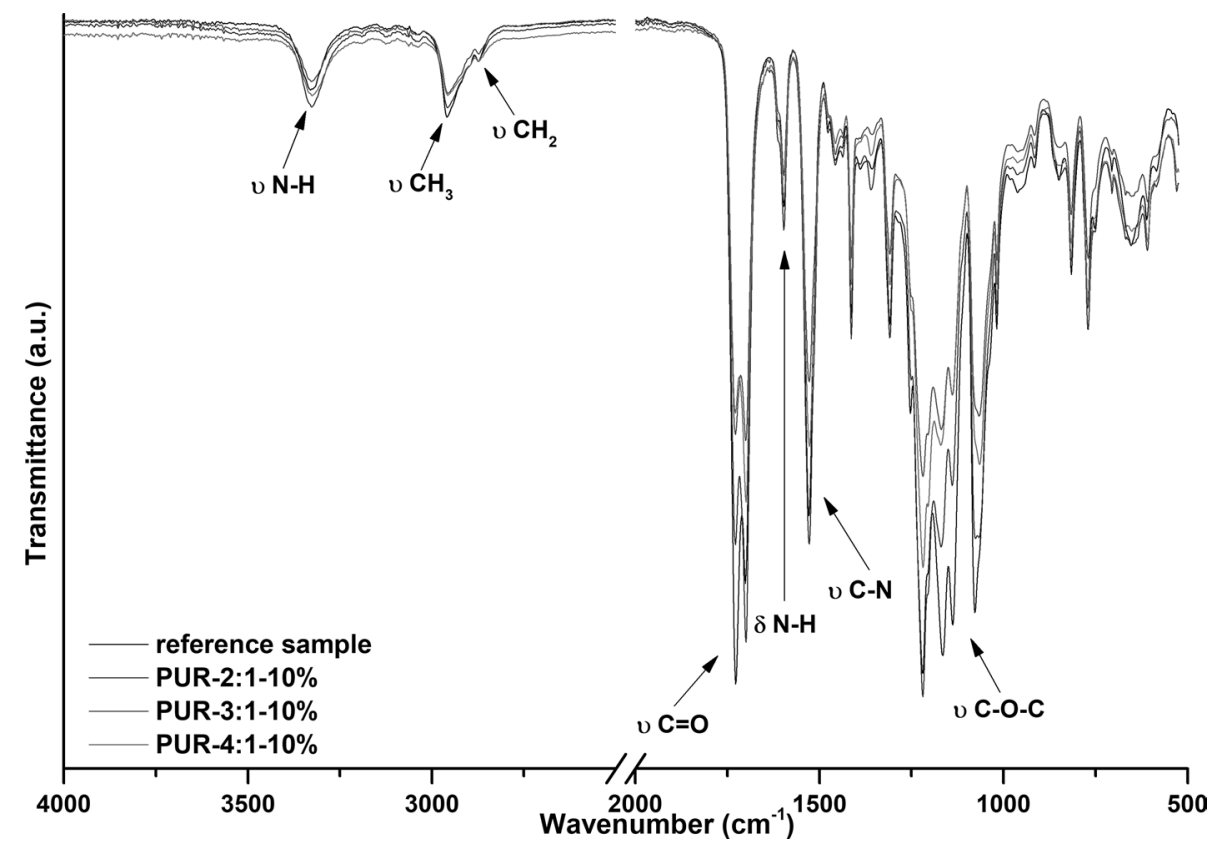


Fig. 11 FTIR spectra of prepared poly(ester urethane) $\mathrm{s}$ in which polyol has been partially replaced by $15 \mathrm{wt} \%$ of glycolysates

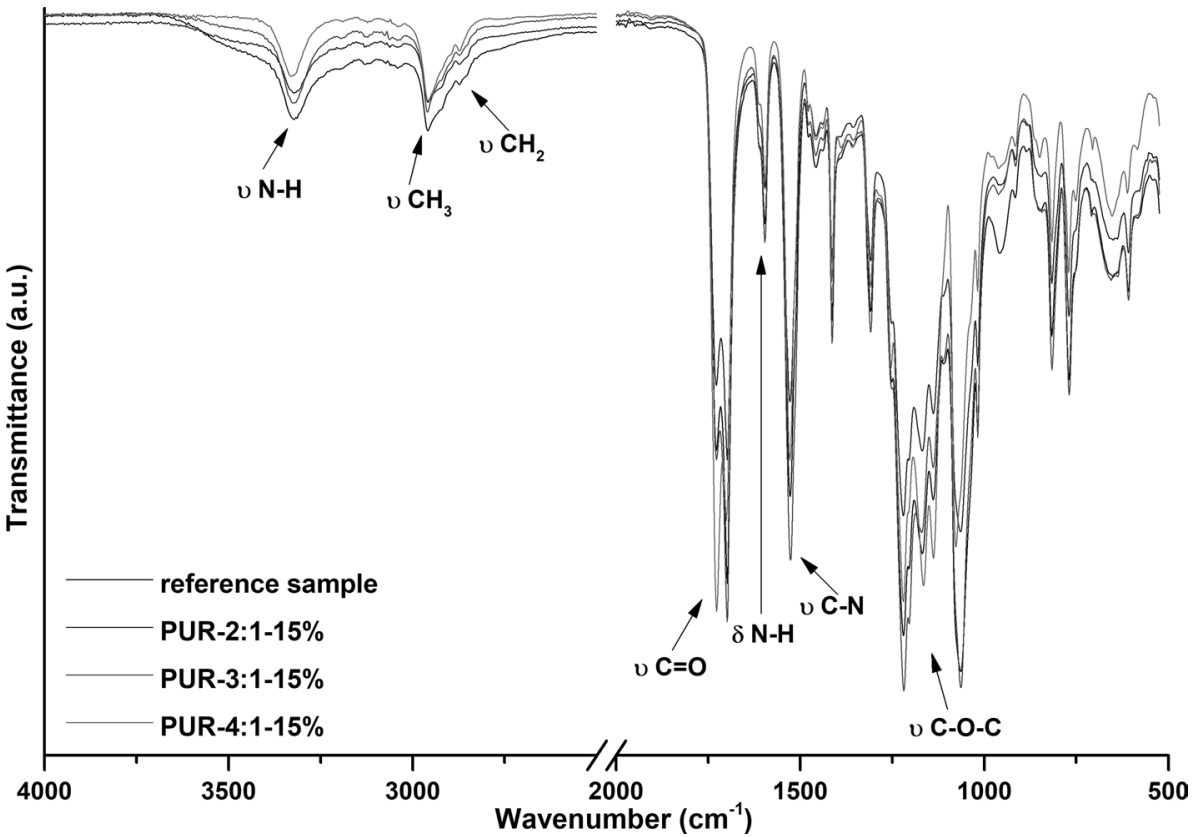

linkage was observed at $1527 \mathrm{~cm}^{-1}$. The characteristic stretching vibration of $\mathrm{C}-\mathrm{O}-\mathrm{C}$ bond occurred in the $1140-1220 \mathrm{~cm}^{-1}$ region. The peaks at the wavenumbers from 1360 to $1477 \mathrm{~cm}^{-1}$ are characteristic bending vibrations of methyl and methylene groups derived from the polyol chain [38]. In the comparable region, deformation vibration of $-\mathrm{CH}_{3}$ groups and bonds between the carbon atoms were detected [15]. The asymmetric and symmetric stretching vibrations of $\mathrm{C}-\mathrm{H}$ groups $\left(-\mathrm{CH}_{2}-\right.$ and $\left.-\mathrm{CH}_{3}\right)$ were present at 2957 and 2873, respectively. Based on the comparative analysis of FTIR spectra for poly(ester urethane)s obtained by using 10 and 15 wt \% of glycolysates, it was concluded that all prepared materials had similar chemical structure with slight but noticeable differences.

In Fig. 12, the values of hardness and rebound resilience of poly(ester urethane)s synthesized with $10 \mathrm{wt} \%$ of glycolysates and those in which polyol was replaced with $15 \mathrm{wt} \%$ of glycolysate intermediates are presented. As mentioned earlier, glycolysates contribute hard segments to the polyurethane structure. This results in the structure
Fig. 12 Comparison of hardness and rebound resilience measured in the obtained polyurethanes
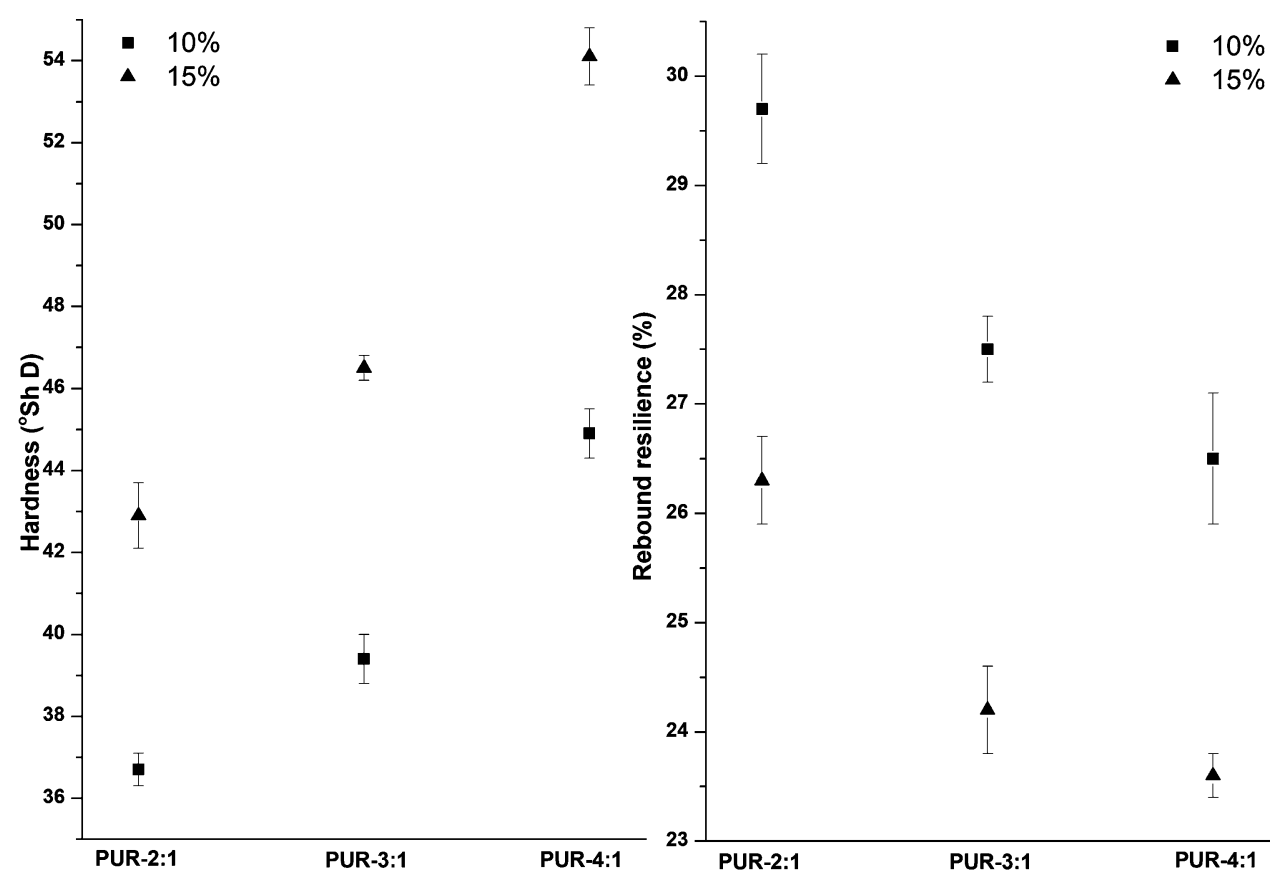
characterized by higher chemical branching and even crosslinking [39]. The hardness values increased with the increasing content of hard segments, so the highest hardness was observed in polyurethanes synthesized with the use of glycolysates with higher EG/PA 6.6 ratios (i.e. $4: 1$ ). It should be noted that the increased shear of glycolysate intermediates in the polyol mixture resulted in the higher value of polyurethane hardness. It can also be seen that the values of hardness and Young's modulus followed the same tendency, which is connected to the hard segment content. The reverse tendency was observed in the case of rebound resilience. With the increasing amount of hard segments, rebound resilience decreased.

The results from the static mechanical testing are presented in Table 6. Both tensile strength and elongation at break were comparatively low due to the incorporation of hard segments from glycolysate intermediates into the chemical structure of poly(ester urethane)s. The tensile strength of all obtained polyurethanes ranged from 5.99 \pm 0.14 to $7.46 \pm 0.11 \mathrm{MPa}$ for PUR-2:1-10\% and PUR$4: 1-10 \%$, respectively. As can be seen, the tensile strength slightly increased as the concentration of glycolysates and the excess of ethylene glycol increased. It could be related to the disturbance of domain structure or the lack of strain-induced crystallization of soft segments. The elongation at break decreased when the petrochemical polyol was replaced with glycolysate intermediates. Apart from the hard segment content, the introduction of compounds with different chain lengths, such as glycolysates, decreased the chain mobility [39]. Consequently, due to the content of glycolysate intermediates, the obtained poly(ester urethane)s were characterized by a lower elongation at break. Moreover, the Young's modulus increased as a result of adding more glycolysate intermediates and the excess of EG to replace the petrochemical macrodiol. The values of this parameter ranged from 93.4 to $117.4 \mathrm{MPa}$ for PUR-2:1-10\% and PUR-4:1-15\%, respectively. This is probably due to the fact that higher chain branching caused greater stiffness of the samples. It should also be pointed out that increasing the amount of hard segments leads to the higher brittleness of the obtained materials.

\section{Conclusions}

In this paper the glycolysis and amino-glycolysis of polyamide 6.6 (PA 6.6) are described. The excess of ethylene glycol (EG) as well as the mixture of ethylene glycol and triethylenetetramine (TETA) were effectively used as decomposing agents during the chemical decomposition of polyamide 6.6. The presented method does not require the use of elevated pressure. In the aforementioned processes, the mixtures of low-molecular-weight compounds were obtained, as confirmed by FTIR spectroscopy. The spectral analysis showed that the molecules with the hydroxyl and amine groups were present among the obtained products. The characteristic absorption bands corresponding to partially unreacted decomposing agents were observed. The variable amounts of EG and TETA effected changes in the hydroxyl and amine numbers. In the case of glycolysates, a distinct increase in the hydroxyl number, and a decrease in the amine number occurred. The low value of calculated number- average molecular weight $(90-250 \mathrm{~g} / \mathrm{mol})$ serves as evidence of satisfying yield. On the basis of rheological measurements, the flow and viscosity curves were constructed for the prepared products. In the present study, the rheological behavior of fluids was described by using the Ostwald-de Waele or Hershel-Bulkley mathematical model, in dependence on the value of the coefficient of determination. All products have been classified as non-Newtonian fluids. The glycolysates obtained at $50{ }^{\circ} \mathrm{C}$ for the mass ratios of $4: 1,5: 1$ and $6: 1$ displayed dilatant behavior. The other analyzed fluids exhibited shear thinning at all temperatures tested.

Novel poly(ester urethane)s were successfully synthesized with glycolysate intermediates originating from the recycled polyamide 6.6 . Selected glycolysates (EG:PA6.6 weight ratios equal $2: 1,3: 1$ and 4:1) replaced the commercially used polyol in the amount of 10 or $15 \mathrm{wt} \%$. The absorption bands attributable to the vibrations of urea bond were observed in the registered FTIR spectra. All
Table 6 Comparison of tensile strength, elongation at break and Young's modulus of prepared poly(ester urethane)s

\begin{tabular}{llrr}
\hline Code of sample (\%) & Tensile strenght (MPa) & Elongation at break (\%) & \multicolumn{1}{c}{$\begin{array}{c}\text { Young's } \\
\text { modulus } \\
(\mathrm{MPa})\end{array}$} \\
\hline PUR-2:1-10 & $5.99 \pm 0.14$ & $19.72 \pm 0.52$ & $93.4 \pm 1.8$ \\
PUR-2:1-15 & $7.13 \pm 0.40$ & $9.39 \pm 0.34$ & $104 \pm 2.6$ \\
PUR-3:1-10 & $6.39 \pm 0.30$ & $15.03 \pm 3.30$ & $99.1 \pm 1.8$ \\
PUR-3:1-15 & $6.73 \pm 0.34$ & $7.87 \pm 1.11$ & $110 \pm 3.6$ \\
PUR-4:1-10 & $7.46 \pm 0.11$ & $18.55 \pm 1.41$ & $104.3 \pm 2.4$ \\
PUR-4:1-15 & $7.05 \pm 0.09$ & $7.24 \pm 0.11$ & $117.4 \pm 3.5$ \\
\hline
\end{tabular}


prepared materials displayed similar chemical structure, with slight but noticeable differences. It was also observed that the values of hardness and Young's modulus increased with the increasing content of glycolysates. The tensile strength of all obtained polyurethane materials ranged from $5.99 \pm 0.14$ to $7.46 \pm 0.11$, thus the results are not significantly different. The downward tendency in the values of elongation at break and rebound resilience has been noticed for the polyurethanes synthesized with a different excess of ethylene glycol. This finding can be explained by the introduction of hard segments into the chemical structure of polyurethanes via the addition of glycolysates.

Based on the obtained results, it can be concluded that the proposed method of polyamide 6.6 (PA 6.6) decomposition is an efficient chemical pathway that can satisfy the present trend in polymer waste management, i.e. the reduction of unfavorable environmental impacts caused by these materials. The obtained decomposition products are suitable for being reused in the synthesis of new polymers, especially polyurethanes. As demonstrated in this study, the application of glycolysate intermediates in the synthesis of polyurethanes, as a part of polyol mixture, resulted in obtaining materials with satisfactory properties.

Funding This research did not receive any specific grant from funding agencies in the public, commercial, or not-for-profit sectors.

\section{Compliance with Ethical Standards}

Conflict of interest The authors declare that they have no conflict of interest.

Open Access This article is distributed under the terms of the Creative Commons Attribution 4.0 International License (http://creativeco mmons.org/licenses/by/4.0/), which permits unrestricted use, distribution, and reproduction in any medium, provided you give appropriate credit to the original author(s) and the source, provide a link to the Creative Commons license, and indicate if changes were made.

\section{References}

1. Plastics Europe (2017) http://www.plasticseurope.org. Accessed 23 Nov 2017

2. Błędzki A (1997) Recykling materiałów polimerowych. WNT, Warszawa

3. Nemade A, Mishra D, Zope V (2011) Chemical recycling of polyamide waste at various temperatures and pressures using high pressure autoclave technique. J Polym Environ 19:110

4. European Commission (2018) http://ec.europa.eu/environmen t/waste/landfill_index.htm. Accessed 10 Jan 2018

5. Kim K, Dhevi D, Lee J, Cho Y, Choe E (2006) Mechanism of glycolysis of nylon 6,6 and its model compound by ethylene glycol. Polym Degrad Stab 91:1545-1555

6. IHS Markit (2018) http://www.ihs.com/products/report-pepre view-2015-06-polyamide-nylon-6-and-66.html. Accessed 10 Jan 2018
7. Kodal M (2016) Polypropylene/polyamide 6/POSS ternary nanocomposites: effects of POSS nanoparticles on the compatibility. Polym 105:43-50

8. Bakkali-Hassani C, Planes M, Roos K, Wirotius A-L, Ibarboure E, Carlotti S (2018) Synthesis of polyamide 6 with aramid units by combination of anionic ring-opening and condensation reactions. Eur Polym J 102:231-237

9. Najafi M, Nasri L, Kotek R (2017) High-performance nylon fibers. In: Bhat $\mathrm{G}$ (ed) Structure and properties of high-performance fibers. Woodhead Publishing, Sawston

10. Singh R, Kumar R, Ranjan N, Penna R, Fraternali F (2018) On the recyclability of polyamide for sustainable composite structures in civil engineering. Compos Struct 184:704-713

11. Singh R, Fraternali F, Bonazzi G, Hashmi MSJ, Kumar R, Ranjan N (2018) Investigations for development of feed stock filament of fused deposition modeling from recycled polyamide. In: Reference Module in Materials Science and Materials Engineering

12. Albrecht W (1964) Tworzywa sztuczne-poliamidy. WNT, Warszawa

13. Lozano-González J, Rodriguez-Hernandez T, Gonzalez-De Los Santos E, Villalpando-Olmos T (2000) Physical-mechanical properties and morphological study on Nylon-6 recycling by injection molding. J Appl Polym Sci 75:851-858

14. Calvo-Correas T, Ugarte L, Jutrzenka Trzebiatowska P, Sanzberro R, Datta J, Ángeles Corcuera M, Eceiza A (2017) Thermoplastic polyurethanes with glycolysate intermediates from polyurethane waste recycling. Polym Degrad Stab 144:411-419

15. Kopczyńska P, Datta J (2016) Single-phase product obtained via crude glycerine depolymerisation of polyurethane elastomer: structure characterisation and rheological behaviour. Polym Int 65:946-954

16. Datta J, Kopczyńska P, Simon D, Rodriguez J (2018) Thermochemical decomposition study of polyurethane elastomer through glycerolysis route with using crude and refined glycerine as a transesterification agent. J Polym Environ. 26:166-174

17. Grzebieniak K, Wesołowski J (2004) Glycolysis of PET waste and the use of glycolysis products in the synthesis of degradable co-polyesters, fibres text. East Eur 12(2):19-22

18. Pardal F, Tersac G (2006) Reactivity of polyesters in glycolysis reactions: unexpected effect of the chemical structure of the polyester glycolic unit. Polym Degrad Stab 91(11):2809-2812

19. McKinney R (1994) Ammonolysis of nylon. US Patent 5302756

20. Kalfas G (1998) Mathematical Modeling of the depolymerization of polyamide mixtures-Part I: kinetic mechanism and parametric studies in batch reactors. Polym React Eng 6(1):41-67

21. Meyer A, Jones N, Lin Y, Kranbuehl D (2002) Characterizing and modeling the hydrolysis of polyamide-11 in a $\mathrm{pH} 7$ water environment. Macromolecules 35:2784-2798

22. Patil D, Madhamshettiwar S (2014) Kinetics and thermodynamic studies of depolymerization of nylon waste by hydrolysis reaction. J Appl Chem. https://doi.org/10.1155/2014/286709

23. Wang Y, Zhang Y (2014) Hydrolytic degradation of monomer casting nylon in subcritical water. Polym Degrad Stab 110:312-317

24. Wang X, Wang Z, Liang S, Jin Y, Lotz B (2018) Surface nanostructure of polyamide 6 film by hydrothermal treatment. Appl Surf Sci 442:595-601

25. Zhao X, Zhan L, Xie B, Gao B (2018) Products derived from waste plastics (PC, HIPS, ABS, PP and PA6) via hydrothermal treatment: characterization and potential applications. Chemosphere 207:742-752

26. Huczkowki P, Kapko J, Olesiak R (1978) Degradation of nylon-6 in ethylene glycol. Polymer 19:77-80 
27. Hommez B, Goethals E (1998) Degradation of nylon- 6 by glycolysis. Part I: identification of degradation products. J Macromol Sci Pure Appl Chem 35:1489-1505

28. Hong J, Choi C, Ramasundaram S, Anand Prabu A, Lee J, Kim K, Yang H, Lee D (2008) Studies on the recycling of glycolyzed nylon 66 using novel chain extenders. Polym Degrad Stab 93:392-400

29. Kopczyńska P, Datta J (2017) Rheological characteristics of oligomeric semiproducts gained via chemical degradation of polyurethane foam using crude glycerin in the presence of different catalysts. Polym Eng Sci 57(8):891-900

30. Charles J, Ramkumaar G, Azhagiri S, Gunasekaran S (2009) FTIR and thermal studies on Nylon-66 and 30\% glass fibre reinforced Nylon-66. J Chem 6(1):23-33

31. Franck A (2010) Understanding rheology of stuctured fluids. TA Instruments, New Castle

32. Björn A, Segura P, de La Monja A, Karlsson J, Ejlertsson B, Svensson (2012) In: Kumar S (ed) Rheological characterization. Biogas

33. Asif A, Hu L, Shi W (2009) Synthesis, rheological, and thermal properties of waterborne hyperbranched polyurethane acrylate dispersions for UV curable coatings. Colloid Polym Sci 287:1041-1049
34. Głowińska E, Datta J (2014) A mathematical model of rheological behavior of novel bio-based isocyanate-terminated polyurethane prepolymers. Ind Crops Prod 60:123-129

35. Datta J, Kasprzyk P, Błażek K, Włoch M (2017) Synthesis, structure and properties of poly(ester-urethane)s obtained using biobased and petrochemical 1,3-propanediol and 1,4-butanediol. J Therm Anal Calorim 130(1):261-276

36. Oprea S (2009) Structure and properties of cross-linked polyurethane. Adv Polym Technol 28(3):165-172

37. Jutrzenka Trzebiatowska P, Echart A, Correas T, Eceiza A, Datta J (2018) The changes of crosslink density of polyurethanes synthesised with using recycled component. Chemical structure and mechanical properties investigations. Prog Org Coat 115:41-48

38. Nikje M, Nikrah M (2007) Glycerin as a new glycolysing agent for chemical recycling of cold cure polyurethane foam wastes in "split-phase" condition. Polym Bull 58:411-423

39. Kopczyńska P, Calvo-Correas T, Eceiza A, Datta J (2016) Synthesis and characterisation of polyurethane elastomers with semi-products obtained from polyurethane recycling. Eur Polym J 85:26-37 